\title{
STATISTICAL CONTROLS AND THE REGULATION OF AIR CARGO
}

\author{
Marc J. Feldstein*
}

I

\section{Statistics as a Regulatory Device}

The functioning of a regulatory agency is increasingly dependent upon adequate statistical work by its staff. The broad trend of social and economic legislation which was gaining momentum since the last quarter of the nineteenth century required factual information regarding economic problems. Economics was emerging from the era of descriptive "philosophic" essays into the "scientifically" objective era of quantitative studies, with mathematics and statistics becoming the chief tools of investigation. The quest for facts became a strong drive, permeating practically all facets of economic legislation. The courts were attuning themselves more and more to the importance of reliable factual data as the basis for decisions. The "Brandeis" way of preparation of cases for litigation and of brief-writing took a strong hold on a substantial proportion of lawyers. The administrators of the numerous regulatory commissions required factual materials as the basis to place their actions above the level of "capriciousness" and "arbitrariness" on the one hand, and on the other hand to give their actions the stamp of the new respectability.

Ideally the work of a statistician in a regulatory agency begins when a need has arisen to find an answer to the question: what is wrong with a given situationi.e., definition of the problem situation, its sçope and significance. Then follows the question: what do we need to know to work out some means of solving the problem-i.e, development of the factual basis of data pertinent to the problem. Then several alternate plans are formulated and statistics are relied upon to evaluate the probable end-results of each of the alternative solutions. After the "best" plan is decided upon, a directive is formulated to put it in operation. The job of a statistician up to that point is only half done. The statistician must develop a system of continuous check on the working out of that directive, that is, means of continuous control of the operations under that directive. And finally, he must make provision for periodic evaluation of the results of operations in terms of their achieving the desired ends.

The statistician is not a policy maker. He is a tool of an administrator, who in turn works within the framework of the broad objectives laid down by the specific organic acts passed by the legislature. At the time organic acts for establishment of

- B.A. I929, M.A. 1932, Western Reserve University. Statistician, Accounting and Rates Division, Civil Aeronautics Board. Contributor to statistical, economic, and legal periodicals. The views expressed herein are those of the writer and consequently do not necessarily reflect the views of any member of the Civil Aeronautics Board or of the Board's staff. 
a given regulatory agency are passed by the legislature, the factual basis is practically never complete enough to allow the legislators to spell out the details even if they wanted to do it. Some definite guides, however, to this spelling out are, as a rule, stated by the legislature. ${ }^{1}$

Regulatory agencies are created to cope with the fast-growing facets of our economy. The statement of policy in the organic act usually includes some broad provision for use of political judgment- "informed judgment" on the part of the regulatory agency, such as, for instance, considerations of "public interest" or "public convenience and necessity." In addition, the legislature not only sets out general standards but also leaves room for defining by the regulatory agency of administrative standards which will allow the parties subject to regulation to know in advance what they can or cannot legitimately do. Such legislative and administrative standards may be in parts procedural in nature, in parts, substantive and statistical. ${ }^{2}$

\section{The Growth Pattern of Air Transportation}

The problems in a growing industry change with time. In air transportation these changes were best characterized by the developmental transition from the simple formative period of the Thirties to the complex struggles of the late Forties. During the Thirties the major problems of air transportation were the need for expanding geographically the infant industry, for stabilizing it on sounder financial grounds, for developing operating patterns, and for experimenting with practically all aspects of operating routines. There was abundant room for growth and development of individual carriers. The carriers needed subsidy to get established in the field; they needed a network of routes; they needed simple regulatory patterns to facilitate operations; they needed simple guidance. The present pattern of air transportation in the United States is a result of rapid extension of routes and expansion of carriers' systems, which systems grew more or less by their own impetus. The carriers, in competition with one another, tried to establish and strengthen their strategic position in the national economy to the best of their abilities. True, there were checks on these expansions, there were administrative acts and pressures enacted to channelize their development to serve "public interest" and "public convenience and necessity," but these checks, administrative acts and pressures, spread over the last ten years, do not fall into a consistent pattern focused on the development of an industry. ${ }^{3}$

${ }^{1}$ It was a failure to spell out sufficiently definite guides, of course, which led to the termination of the National Industrial Recovery Act, 48 STAT. I95 (1933), as amended.

${ }^{2}$ Perhaps the most significant administrative standards of this character were those of the Office of Price Administration. See David F. Cavers, et al., Problems in Price Control: Pricing Standards (Historical Reports on War Admisistration, Gen. Pub. No. 7, 1947); Nathaniel L. Nathanson and Harold Leventhal, Problems in Price Control: Legal Phases (Historical Reports on War Administration, Gen. Pub. No. Ix, I947).

${ }^{3}$ See Sweeney, Policy Formation by the Civil Aeronautics Board, 16 J. AIR L. AND Com. 127, 147 (1949); Westwood, Choice of the Air Carrier for New Air Transport Routes, I6 Geo. WasH. L. Rev. 1, 159 (1947-r948). 
Recently new and dynamic factors have entered into the air transportation picture which profoundly affect regulatory needs. ${ }^{4}$ Among these factors are the postwar expansion of capacity, the development of new plane types, the challenge of "air coach" operations from the irregular passenger carriers and from some of the established carriers as well, increased competition from fellow grandfather carriers, diminution of the proportion of mail payments in the total revenue of carriers until recently, and, most of all, the startling rise of the independent all-cargo carriers. Moreover, the cargo picture is not a simple one in as much as some of the mailpassenger carriers have transported volume amounts of freight, and in recent months one such carrier has become the principal mover of this type of traffic.5

These facts raise difficult problems with respect to the administration of air mail subsidies, for which domestically only the certificated passenger carriers are eligible. ${ }^{6}$ The extent to which these carriers may use funds received from the government to offset possible losses from air freight remains an unsettled issue. This issue is made all the more difficult to resolve because of (I) the grandfather carriers' historical reliance on subsidy and their determined effort to block the determination of "joint costs," and (2) the fact that competing independent freight carriers have no subsidy backlog on which to rely. Obviously the second of these factors must and has received consideration by the Civil Aeronautics Board, but any final determination not to consider the over-all financial needs of passenger carriers is a step that may not be taken lightly.

\section{III}

\section{Basic Reporting Needs ${ }^{7}$}

It is in this context that we face the problem of the statistical needs of the regulating agency, particularly with respect to the impact made upon the industry by the growth of air cargo. If at the outset we are to assume that the information requirements of the agency are now the same simple ones that existed in the formative period of the Thirties, a subsequent Board attempt to develop a rational air transport system may well be hindered by its own reporting devices.

The history of $\mathrm{CAB}$ statistical procedures has a bearing on the problems now at hand. Under the Civil Aeronautics Act of $193^{8}$, the agency had been granted rather broad powers to prescribe a reporting system for the carriers. This reporting system was intended to yield data for the carrying out of regulations. The reporting sys-

'This was emphasized by the Task Force Report on Regulatory Commissions (Appendix N), prepared for the (Hoover) Commission on Organization of the Executive Branch of the Government, January, I949, at page 74 .

${ }^{5}$ Recent recurrent monthly reports of the Civil Aeronautics Board show that American Airlines freight traffic is now greater than that of Slick Airways, the largest of the independent cargo carriers.

'The tentative opinion of the Board in the Air Freight Certificate Case, Docket No. 8ro, makes no provision for subsidy for the independent freight carriers, and none of these carriers has as yet seriously proposed that subsidy be granted it. Order Serial No. 2759, April 25, 1949.

${ }^{7}$ In the following discussion we concern ourselves with the thought patterns underlying the statistical design of $\mathrm{CAB}$ statistics, rather than the details of statistical forms, definitions, etc. Given an adequate framework, the craftsmanship of a statistician will take care of technical points. 
tem in operation between 1938 and 1946 was adapted from the system for reporting on mail operations on a post-audit basis employed by the Post Office Department, which had jurisdiction over air mail. The system centered upon the chief interest of the Post Office-namely, the cost of carrying mail to be defrayed by the Post Office- Department. With the mail rates having become the vehicle of underwriting the operation of the carriers under the Act of $193^{8}$, the salient points of the reporting system did not have to change too much. The determination of the mail rate, based on the need of the carrier, continued to be the center of emphasis; while the industry continued in its infancy, the reporting system carried over from the Post Office appeared to serve reasonably well.

By 1945 its inadequacies became sufficiently pronounced so that a basic revision and extension of the reporting system was undertaken by the CAB's Bureau of Economic Regulation, with the cooperation of a committee appointed by the Air Transport Association of America, the trade organization of the established mail-passenger carriers. This revision, entitled a "Uniform System of Accounts for Air Carriers" (Form 4I), was put into effect on January I, 1947. It extended the scope of reporting, sharpened the definition of accounts, improved substantially the workability of the system, and made it better adaptable to the needs of the regulatory process. The exhaustive work on revision of the system was a significant attempt to introduce uniformity into the reporting of the different carriers, thus making the data in these reports comparable among the carriers as well as among the different periods. The reporting system has remained, however, essentially a retrospective post-audit system. The need for further revision of the reporting system has been voiced by the CAB staff, and by other agencies concerned with air commerce. But the pressure of other work and the tremendously time-consuming process of clearance of such a basic revision delays the undertaking. Meanwhile, the present design is expanded, revised, and made to serve the needs of the CAB as well as it can.

The present reporting system necessarily requires staff work to be conducted along certain narrow lines. In order to determine the reasonable mail rates for the future, which are the only kind of worth while "permanent" mail rates prescribed by the Board, past operations are analyzed to determine if management has been operating "honestly, economically and efficiently." Lacking the background of broad economic analyses and time and motion studies, the CAB staff takes recourse in the method of comparison between the detailed expenditures of a group of more or less similar carriers to establish some group norms of "efficiency of operations." Serious deviations from such group norms may result in disallowances of particular expenditures for mail rate purposes. These disallowances are intended to protect the interests of the government by cutting down the extent of subsidy and also to aid industry in getting on an even keel by attracting attention of the individual carriers to excessive expenses or inefficient patterns of operation. Projections of these results and trends based on these post-audits are among the factors used for fixing future mail rates.

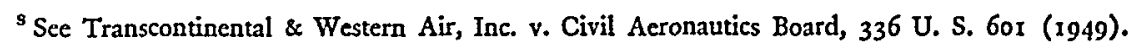


Necessarily a reporting system of this character leads to preoccupation with the "efficiency" of management. The Board finds itself in this anomalous position: "efficiency" of a given carrier is ascertained by comparison of its past operating results with the past results of some comparable carriers. The method of determining efficiency thus fits snugly into the system of post-audit reporting. But in recent times the differences in the "efficiency" of carriers' operations were growing smaller, because of the growing standardization of patterns of operation, thus cutting the ground from beneath the preoccupation with "efficiency."

Far more attention needs to be directed toward the issue of whether a carrier's operations are "economical" in the language of Section 406(b) of the Civil Aeronautics Act. $^{.}$In one of the most significant addresses of recent years, Chairman O'Connell has stated the question in this form: $:^{10}$

The words "honest, economical and efficient" as used in Section 406(b) are usually spoken in one breath and it is a little difficult to differentiate between at least the last two. To my mind, the word "efficiency" represents a concept of output relative to input. This would be judged primarily by the amount of transportation produced by a given number of employees, the amount of transportation which can be generated by a given amount of capital applied to the business, etc. On the other hand, "economical" connotes for me the questions of whether or not the carrier and the carrier's management arrive at decisions which make reasonable economic sense. For example, are they offering an amount of capacity which is based on reasonable levels of demand or are they offering capacity which is far in excess of that demand. Is their pricing, that is their rates and fares for the carriage of passengers and property, so designed as to maximize their revenues and their profits or are they established with no clear objective in mind and allowed to drift along as best they may.

To me the word "economical" implies an ability to plan sufficiently far in advance as to be prepared to meet the contingencies of both operations and traffic at the time that they may arise, granted, of course, that no forecasting or planning can be perfect. An economical management is one which would exercise a reasonable care and prudence in terms of the financial plans that it worked out. These plans should take into consideration the basic nature of air transportation and the possibility, if not probability, that the industry and the particular carrier concerned will be faced sooner or later with difficult periods during which the impact of a heavy debt structure and related fixed charges will be particularly onerous, pernaps crushing.

I am not sure that some of our air carriers have an economic management, using the term in the sense of the word just discussed. . . .

This indicates at least the position of the present Board Chairman that individual carriers, in order to satisfy the statutory test of "economical" management, should formulate long-range plans which recognize the growth and development factors of their own systems as well as of the industry. But this places no lighter burden on the Board; on the contrary, this conclusion makes it imperative that the Board formulate a comprehensive plan for air transportation which would encompass not

\footnotetext{
${ }^{\circ} 52$ Stat. 998,49 U. S. C. $\$ 486$ (1946).

${ }_{10}$ Air Mail Pay Under the Civil Aeronantics Act of 1938 (an address before the Association of the Bar of the City of New York, March 23, 1949).
} 
only the growth and development of each diverse part of the industry but also that of the industry as an entity. ${ }^{11}$ Without such a plan, "regulation" in the sense contemplated by the Civil Aeronautics Act is well nigh impossible.

But the "economical" test is difficult to make with only past results of operations to examine. Economic planning of future operations is essentially a matter of managerial policies which determine the future operations. It is in this framework that the desirability for "prospective" reporting, in addition to "retrospective" reporting, becomes apparent. If it is posited that the operations of a given carrier must be viewed and analyzed in the context of the entire industry; if the stress in the evaluation is to be divided between the analysis of the actual operations and that of managerial policies; and if we are to view air transportation as a genuine "growth industry" which expands and creates new patterns-that is, such patterns which cannot be explained merely as expansion or continuation of old patterns-then the need for prospective reporting and the limitations of post-audit reporting become obvious.

By prospective reporting is meant the submission of statistical data by the carrier estimating the salient facts of operations during a future period, say, a year. The carrier should be required to submit every quarter its estimates for the following year, correcting them as the need arises. Thus, $\mathrm{CAB}$ would have in its files a complete forecast by the carrier of the traffic and cost data; data on equipment and its utilization; data on financing of operations; and reflection of the effect of handicaps and atypical situations as they are evaluated and felt at the time of their occurrence and in successive periods. In contrast, the present reporting system used by $C A B$ is based squarely on the traditional notions of accounting. When the problems get out of the rather rigid area of "taxing, credit and legal purposes," 12 and when this system attempts to meet wider requirements of economic planning and policy making, its shortcomings appear.

Prospective reporting will become a definite deterrent to the present widespread practice of making ad hoc estimates and claims for separate proceedings-estimates and claims, frequently of a contradictory nature, fitting the carrier's advantage in a particular proceeding. In addition to this worth while deterrent, prospective reporting will allow direct comparison between planned and actual operations, thus raising danger signs whenever the operations do not work out according to plan. Prospective reporting greatly facilitates the managerial control of operations and tends to instill in the management the attitude of critical self-evaluation. It tends to simplify and make more effective the administrative and regulatory process by supplying crucial

${ }^{11}$ The Report to Congress on Regulatory Commissions by the (Hoover) Commission on Organization of the Executive Branch of the Government sets out the following conclusion under the heading What Is Wrong with Independent Regulatory Commissions:

"The quantity of work in the regulatory field at the top level has been so great that the commissions have often neglected their promotional and planning functions." A Report to tHE Congress BY the Commission on Organization of the Executive Branch of Government 4 (March, 1949).

12 Readers are referred to Billy E. Goetz, Management, Planning and Control (1949), particularly chapter 12 , for a penetrating discussion of the relation of statistics to managerial control. 
data in a timely manner. In the analysis of interaction among carriers in terms of a comprehensive plan for air transportation, prospective reporting will give the $C A B$ a means of anticipating difficulties and the need of regulatory or corrective action, on a preventive rather than a curative basis. Under present circumstances, the Board must wait until the problem situations are brought to its attention, thus reducing itself to the position of an umpire rather than that of a planner of air transportation on a national scale. ${ }^{13}$

The power of $C A B$ to require prospective reporting can hardly be questioned in principle. The inclusion of some specific details may be objected to by the carriers, but the substantial advantages which would be derived from instituting the system of prospective reporting so far outweigh the difficulties of its installation, that one is surprised that this reporting pattern has not been consistently employed by the Civil Aeronautics Board.

The changing influence of mail revenues ${ }^{14}$ and the growing impact of revenues from cargo have already been suggested. Quite apart from the merits or demerits of prohibiting the use of subsidy to offset freight losses, ${ }^{15}$ or the extent of that use, one thing does seem clear. The Board should be sure that the statistical materials compiled by its staff will squarely face the problem of joint costs and show the cost of carrying either freight, express, mail, or passengers, for in the absence of quantitative data the decision on the merits otherwise will be made on the basis of conjecture and emotion.

Obviously the impact of the air freight "industry" or sub-industry upon air transportation will go far beyond the matter of statistical procedures. It may well be that one impact will be the realization that the simple $a d$ hoc approach to air transportation problems, perhaps necessary and valuable in an earlier period, has outworn its usefulness. ${ }^{10}$ This conclusion will be most difficult to escape once it is assumed that the prime regulatory responsibility is the fitting of diverse parts into a rational total pattern of air transport. Not only does intelligent administration of air mail

${ }^{13}$ See Durham and Feldstein, Regulation as a Tool in the Development of the Air Freight Industry, 34 V.. L. Rev. 769, 808 (1948); see also Sweeney, Policy Formation by the Civil Aeronautics Board, I6 J. Air L. AND CoM. 127, I47 (1949).

${ }^{14}$ According to the recent Report on Air Mail Subsidy of the House Committee on Post Office and Civil Service, mail pay represented 37.8 per cent of all operating revenues in 1938 but only 7.7 per cent in the first nine months of 1947. H. R. REP. No. 1958, 8oth Cong., 2d Sess. 2 (1948). In the case of five carriers-Braniff, American, Delta, Eastern, and National-the 1947 proportion of revenues from mail pay was 4 per cent or less. Id. at $4 \mathrm{I}$.

${ }_{10}$ The Task Force Report (Appendix N) on Regulatory Commissions prepared for the (Hoover) Commission on Organization of the Executive Branch of the Government took the position that "mail rates should no longer include any need or subsidy element but should be based on the service rendered. They should reflect a fair allocation of costs between mail, passenger, and freight services." THE TAsK Force Report (Appendix N) on Regulatory Commissions 77 (January, 1949).

${ }^{20}$ The criticism of the (Hoover) Commission on Organization of the Executive Branch of the Govcrnment contained in the report on the regulatory commissions is pertinent:

"The chief criticism that can be made of the regulatory commissions is that they become too engrossed in case-by-case activities and thus fail to plan their roles and to promote the enterprises entrusted to their care. Typical of this is the attitude by which the Civil Aeronautics Board and the Interstate Commerce Commission have approached the problem of building a route structure for the Nation." REPORT, op. cit. supra note II, at 15-16. 
subsidies require reporting of this character, but also it is the sine qua non for integration of the new cargo carriers into the air transport system and for the evaluation of each carrier's place in any regulatory design for the industry.

\section{IV}

\section{Conclusion}

The Civil Aeronautics Board recently has been under attack in Congress, ${ }^{17}$ in the courts, ${ }^{18}$ and in the press. ${ }^{19}$ It may well be that revision of CAB statistical procedures and objectives to recognize the emergence of air cargo and other new factors in air transportation would gain added and deserved respect for the Board, in spite of the obvious short-run difficulties in taking such a step.

Revision of statistical procedures would appear to be a condition precedent to the recognition of new facts in air transport. This change in regulatory approach should make possible the development of affirmative administrative standards and the rejection of ad hoc determinations with their many inconsistencies. Unlike the past, decisions rendered in this setting would have real value as precedents for future Board action. ${ }^{20}$ Such procedures might well serve as an indication to Congress that monies appropriated for air mail subsidies would be employed in an orderly fashion. Now that the Board finds itself a party to an increased amount of litigation, it may find its position enhanced by a more consistent approach to air transportation. Moreover, reporting changes of the character here discussed would be an additional step toward making the industry aware of the Board's active responsibilities under the Civil Aeronautics Act.

${ }^{17}$ Most important have been the recently completed hearings of the Senatc Committec on Interstate and Foreign Commerce under the chairmanship of Senator Edwin C. Johnson of Colorado. See also H. R. Rep. No. 1958, 80th Cong., 2d Sess. (1948) passim; H. R. Rep. No. 1242, 8oth Cong., $2 d$ Sess. 5 (1948); H. R. Rep. No. 2163, 8oth Cong., 2d Sess. 2 (1948); Sen. Rep. No. 3189, 80th Cong., 2d Sess. 5 ( 1948$)$.

${ }^{18}$ Especially by Justice Jackson in the dissenting opinion in Transcontinental \& Western Air, Inc. v. Civil Aeronautics Board, 336 U. S. 6or (1949).

${ }^{10}$ Press criticism has come principally from the columnists Marquis Childs, Thomas L. Stokes, and Drew Pearson, although a few newspapers, particularly The Washington Post, have been critical.

${ }^{20}$ In this connection, the survey officer on aviation for the Regulatory Commission Committce of the Hoover Commission has made this statement:

"It appears that the Board could have done better in adopting general standards to guide it in handling the many important and novel policy decisions that have come before it. It has been pointed out that its decisions in individual cases have developed little precedent that either the Board or inclustry considers binding. This has made the Board's problem of rendering fair and consistent decisions particularly diffeult." Sweeney, Policy Formation by the Civil Aeronautics Board, I6 J. AIR L. AND Com. 127, 159 (1949). 